\title{
АПРОБАЦИЯ РУССКОЯЗЫЧНОЙ ВЕРСИИ МЕТОДИКИ САМОВОСПРИЯТИЯ ТРУДОСПОСОБНОСТИ
}

\author{
А.Ю. СМИРНОВА \\ ${ }^{a}$ Саратовский национальный исследовательский государственный университет имени Н.Г. Чер- \\ нышевского, 410012, г. Саратов, ул. Астраханская, д. 83
}

\section{Approbation of the Russian Version of Self-Perceived Employability Scale}

\author{
A.Yu. Smirnova ${ }^{a}$ \\ Saratov National Research State University, 83 Astrakhanskaya Str., Saratov, 410012, Russian Federation
}

\section{Резюме}

В статье представлены результаты апробации русскоязычной версии Шкалы самовосприятия трудоспособности (Self-Perceived Employability Scale). Русскоязычная версия методики была апробирована на выборке 715 человек. Результаты апробации подтвердили факторную структуру, валидность и надежность психодиагностического инструмента. Факторная структура методики была подтверждена при помощи конфирматорного факторного анализа $\left(\chi^{2}=77.577, \mathrm{df}=29\right.$, $\mathrm{CMIN} / \mathrm{DF} 2.675, p=0.000, \mathrm{GFI}=0.944, \mathrm{AGF}=$ $0.893, \mathrm{CFI}=0.819, \mathrm{RMSEA}=0.057[90 \% \mathrm{CI}$ 0.042-0.072], PCLOSE $=0.216$, HOELTER $=$ 285). 3-факторная структура методики включает шкалы, надежность-согласованность которых следующая: Самооценка работником себя как специалиста и должности в организации ( $\alpha=0.642)$, Самооценка работником себя на внешнем рынке труда $(\alpha=$ $0.595)$, Воспринимаемая ценность профессии на внешнем рынке труда $(\alpha=0.761)$. Коэффициент корреляции при анализе тест-ретестовой надежности составил от $r=0.56$ до $r=$ $0.72, p<0.001$. Конвергентная и дискриминантная валидность методики подтверждена результатами корреляционного анализа, обнаружившего выраженную связь всех суб-

\begin{abstract}
The paper presents the results of approbation of the Russian Version of the SelfPerceived Employability Scale . 715 employees completed the Russian version of the SPE Scale. Research on the representative Russian sample revealed good consistency and test-retest reliability of the SPE Scale (the correlation ranged from 0.56 to 0.72 ), confirmed the factor structure, validity and reliability of the psychodiagnostic tool. Confirmatory factor analysis (CFI) supported the factor structure of the SPE Scale. The CFI results are following: $\chi^{2}=$ 77.577, $\mathrm{df}=29, \mathrm{CMIN} / \mathrm{DF} 2.675, p=0.000$, $\mathrm{GFI}=0.944, \mathrm{AGF}=0.893, \mathrm{CFI}=0.847$, RMSEA $=0.057$ [90\% CI 0.042-0.072], PCLOSE $=0.216$, HOELTER $=285$. The consistency of the subscales as follows: the internal self-perceived employability (alpha reliability coefficients, $\alpha=0.642$ ), the self-valuation outside current organization $(\alpha=0.595)$, the perceived value of the occupation outside current organization $(\alpha=0.761)$. The results on convergent and discriminant validity of the scale are confirmed by the correlation analysis, which shows high score of all subscales of the SPE Scale with a sense of success in professional
\end{abstract}


шкал методики самовосприятия трудоспособности с чувством успешности в профессиональной деятельности (от $r=0.442$ до $r=0.288$, $p<0.001$ для субшкалы Оценка востребованности профессии на рынке труда), Внутренним спокойствием и равновесием $(r=0.308$, $p<0.001)$, Активной стратегией решения проблем $(r=0.385, p<0.001)$, Уровнем профессиональных притязаний $(r=0.395, p<0.001)$, Чувством поддержки социального окружения $(r=0.300, p<0.001)$. Стремление к совершенству и субъективное значение деятельности демонстрируют значимую корреляцию со Способностью трудоустроиться именно внутри организации $(r=0.364, p<0.001)$, но не вне ее. Все субшкалы, в особенности Оценка себя как специалиста в организации ( $r=-0.499, p<0.001)$, отрицательно связаны с Переживанием незащищенности. Результаты эмпирического исследования свидетельствуют о том, что шкала обладает достаточной надежностью и ее применение позволяет получить валидные результаты в эмпирических исследованиях и практике.

Ключевые слова: способность трудоустроиться, самооценка, трудоспособность, субъективная незащищенность в сфере труда, валидность, шкала, переживания, связанные с работой.

Смирнова Анна Юрьевна - доцент, кафедра общей и социальной психологии, факультет психологии, Саратовский национальный исследовательский государственный университет имени Н.Г. Чернышевского, кандидат психологических наук.

Сфера научных интересов: социальная психология, организационная психология, субъективная незащищенность в сфере труда, самовоспринимаемая трудоспособность, валидность, переживания, связанные с работой. Контакты: anna-smirnova-sgu@mail.ru activities (ranging from 0.442 to 0.288 for the perceived value of the occupation outside current organization, $p<0.01$ ), the calm and balance (from 0.308), the active problem-solving strategy $(0.385, p<0.01)$, the level of professional aspirations (0.395, $p<0.01)$, the sense of the social environment support $(0.300, p<0.01)$. The pursuit of excellence and the subjective value of the activity demonstrates significant correlation with the internal self-perceived employability $(0.364, p<0.01)$, but not the external self-perceived employability. All subscales, especially the internal self-perceived employability are negatively correlated with the job insecurity $(-0.499$, $p<0.01$ ). According to the results of our approbation, the Self-Perceived Employability Scale can be considered a reliable and valid psychodiagnostic tool in Russia.

Keywords: self-perceived employability, self-esteem, job insecurity, validity, scale, work-related experiences.

Anna Yu. Smirnova - Associate Professor, Department of General and Social Psychology, Faculty of Psychology, Saratov National Research State University, $\mathrm{PhD}$ in Psychology.

Research Area: social psychology, organizational psychology, job insecurity, perceived employability, validity, work-related experiences.

Email: anna-smirnova-sgu@mail.ru

Современный рынок труда подвержен значительным трансформациям. По прогнозам компании McKinsey (2017), к 2030 г. может потерять работу каждый пятый из ныне трудящихся. Непрерывное обучение и многократная смена профессии становятся неотъемлемой характеристикой профессиональной карьеры работника, а его занятость больше не гарантирована, на протяжении своей профессиональной деятельности многие работники не раз переживают ненормативный кризис занятости (Бендюков, 2007). При этом имеется 
достаточно исследований, подтверждающих, что в одной и той же рабочей ситуации одни работники могут быть подвержены значительному стрессу и переживать из-за угрозы потерять занятость, другие - реализуют блестящую карьеру (Klandermans, van Vuuren, 1999), в том числе не ограничивая себя рамками одной организации (Greenhaus et al., 1990). В связи с этим становится актуальным изучение ресурсов личности в ситуации угрозы потери работы, безработицы, а также восприятия человеком собственной способности сохранить занятость в организации или в ситуации вынужденного увольнения найти новую, не худшую по своим характеристикам работу, в том числе исследование восприятия человеком собственной трудоспособности.

Исследование проблемы восприятия собственной трудоспособности работником может внести вклад в понимание особенностей профессионального самоопределения людей на разных этапах жизненного пути, мотивации профессиональной деятельности, удовлетворенности ею, однако в отечественной психологической литературе не представлены исследования, посвященные самовосприятию трудоспособности, равно как и отсутствуют инструменты для ее измерения, использование которых потенциально возможно в контексте отмеченных тенденций занятости, необходимо в карьерном консультировании, работе организационного психолога, что обусловливает теоретическую и практическую актуальность данной темы.

Трудоспособность традиционно анализируется в правовом поле и в юриспруденции выступает как объективная категория, содержание которой определено ФЗ № 125-ФЗ от 24 июля 1998 г., согласно которому профессиональная трудоспособность - способность человека к выполнению работы определенной квалификации, объема и качества; степень утраты профессиональной трудоспособности, выраженное в процентах стойкое снижение способности работника осуществлять профессиональную деятельность до наступления препятствующего работе заболевания или травмы. В контексте определения возраста, с которого допускается заключение трудового договора (ТК РФ, ст. 63), гарантий при временной нетрудоспособности (ТК РФ, ст. 183), а также дополнительных гарантий занятости инвалидов в рамках ФЗ от 24 ноября 1995 г. № 181-Ф3 «О социальной защите инвалидов в Российской Федерации». В вопросе повышения трудоспособности инвалидов сделано уже немало: в 2012 г. Россией ратифицирована Конвенция ООН о правах инвалидов, Министерство труда и социальной защиты Российской Федерации реализует программы сопровождаемой занятости инвалидов (Минтруд, 2017).

По данным Федеральной службы государственной статистики, уровень безработицы на конец 2020 г. в среднем по Российской Федерации составил $6.1 \%$ от трудоспособного населения, в регионе, где выполнялось исследование, $-6.3 \%$.

Среди безработных доля женщин в январе 2020 г. составила 47.4\%, молодежи до 25 лет - 18.5\%, лиц, не имеющих опыта трудовой деятельности, $21.2 \%$, а в декабре 2020 г. процент безработных женщин составил уже 48.1\%, не имеющих опыта трудовой деятельности $-19.4 \%$.

Эти, казалось бы, невысокие цифры составляют 3487.2 тыс. человек (Федеральная служба государственной статистики, 2020). Официальная статистика 
приводится без учета скрытой безработицы, а также тех работников, чья занятость находится под угрозой.

Нестабильность рынка труда в конце XX в., характерная для ряда европейских стран, привлекла в конце XX - начале XXI в. пристальное внимание зарубежных психологов к трудоспособности как субъективной категории (Hillage, Pollard, 1998; Mallough, Kleiner, 2001; Forrier, Sels, 2003; Fugate et al., 2004; Berntson et al., 2006; Berntson, 2008), хотя попытки анализировать смежные конструкты предпринимались и ранее.

Как субъективная категория трудоспособность (самовоспринимаемая трудоспособность - self-perceived employability) определяется Эндрю Ротвелом и Джоном Арнолдом как оценка работником своей способности сохранить занятость или получить новую, соответствующую личным ожиданиям работу (Rothwell, Arnold, 2007; Rothwell et al., 2008). Именно на это определение мы опираемся в своем исследовании, валидизированная в нашем исследовании методика разработана этими авторами (Rothwell, Arnold, 2007).

В анализе воспринимаемой трудоспособности можно выделить два направления: индивид-центрированный подход, связанный с самооценкой субъектом собственного потенциала для сохранения занятости и поиска новой работы (Fugate et al., 2004; Berntson et al., 2006; Mallough, Kleiner, 2001; Berntson, 2008; Rothwell et al., 2009; Mazalin, Parmac Kovacic, 2015; Pitan, Muller, 2020), и ситуационный, направленный на анализ восприятия субъектом ситуационных факторов: экономической ситуации, особенностей локального рынка труда и организационных факторов (Forrier, Sels, 2003; Kluytmans, Ott, 1999; Vargas et al., 2018; и др.), и именно учет ситуационных факторов отличает воспринимаемую трудоспособность от близкого, но не тождественного конструкта - самоэффективности. Структура рынка труда имеет свои региональные особенности. Ситуации экономического спада или подъема неодинаковы по своим возможностям для трудоустройства, однако действия субъектов труда в одних и тех же условиях значительно различаются: одни выбирают пассивную стратегию, другие активно ищут возможности.

Отмеченные нами тенденции актуализируют важность оценки и развития ресурсов личности, представлений работника о себе как способном эффективно противостоять субъективной незащищенности в сфере труда.

Помимо описанного нами возвращения на рынок труда безработных граждан, самовоспринимаемая трудоспособность также анализируется в следующих ракурсах:

а) выпускников, совершающих первичный выход на рынок труда после окончания учебных заведений (Rothwell et al., 2008; Rothwell al., 2009; Lowden et al., 2011; Mazalin, Parmac Kovacic, 2015; Pitan, Muller, 2020);

б) в контексте изменчивости организационной структуры как способность сохранить занятость в изменяющейся организации, быстро переключаться с выполнения одного вида работы на другой (Rothwell, Arnold, 2007; Berntson, 2008);

в) как способность успешно найти работу после увольнения по инициативе работодателя (Hillage, Pollard, 1998; Forrier, Sels, 2003); 
г) как способность сделать карьеру (Berntson, 2008).

Для российского общества рациональное привлечение молодежи на рынок труда (трудоустройство по специальности, способность быстро найти работу) имеет критическое значение из-за достаточно высокого уровня безработицы среди выпускников, а также массовой практики их ухода из профессии.

Э. Ротвел с соавт. выделяют следующие характеристики, формирующие трудоспособность: знания и навыки, способность управлять собственной карьерой и искать работу (Rothwell, Arnold, 2007). Согласно представленным в литературе эмпирическим данным, восприятие рабочей ситуации и способность трудоустроиться во многом зависят от внутреннего локуса контроля, позитивной аффективности, самооценки, и самоэффективности, а также нейротизма (Kanfer et al., 2001; Pinquart et al., 2003; Moynihan et al., 2003; Forrier, Sels, 2003; Krause, Broderick, 2006; Rothwell et al., 2008; Berntson, 2008; Gardner et al., 2010; Lowden et al., 2011; Mazalin, Parmac Kovacic, 2015).

Имеющиеся эмпирические данные свидетельствуют о гендерных различиях в уровне самовоспринимаемой трудоспособности (мужчины оценивают себя как более трудоспособные, чем женщины (Rothwell, Arnold, 2007; Vargas et al., 2018; Pitan, Muller, 2020)).

Воспринимаемая трудоспособность рассматривается в контексте способности сохранить длительную занятость, гибко адаптируя свои возможности под требования внутриорганизационного рынка труда (Rothwell et al., 2007) или как способность продвигаться по карьерной лестнице (Berntson, 2008). Именно анализ трудоспособности в контексте ее самовосприятия является основным направлением исследований в данный момент (Berntson, 2008; Rothwell et al., 2009; Mazalin, Parmac Kovacic, 2015; Vargas et al., 2018; Pitan, Muller, 2020; Paviotti, 2020).

В контексте теории социального конструкционизма самовосприятие трудоспособности как способности субъекта определить и реализовать свои карьерные перспективы (Berntson, 2008; Fugate et al., 2004; Mazalin, Parmac Kovacic, 2015) зависит от социокультурной группы, к которой принадлежит индивид, что делает необходимым обращение к феноменам конструирования социальных проблем в представлении граждан и коллективной памяти (Емельянова, 2016), а также дихотомией феноменов «психологической защищенности - незащищенности», в том числе субъективной трудовой незащищенности (Смирнова, 2018). Воспринимаемая трудоспособность является многогранным феноменом и может быть понята как функция взаимовлияний между объективной ситуацией, ее ментальной реконструкцией и субъективными характеристиками личности. Высокая воспринимаемая трудоспособность выступает альтернативой гарантий занятости «employability security» (Kanter, 1993) и позволяет работнику обрести психологическую защищенность в условиях флексибильности организационной и внешнеорганизационной ситуации (Bernstrøm et al., 2019).

Согласно определению Э. Бернтсона (Berntson, 2008), самовоспринимаемая трудоспособность - индивидуальное восприятие собственной возможности получить новую работу с аналогичными имеющимися или лучшими условиями. 
В отечественной науке подобному ракурсу анализа трудоспособности, к сожалению, не уделяется достаточное внимание. Анализируется влияние кризиса на субъективное благополучие, а также ресурсы совладания с экономическим кризисом, такие как смысложизненные ориентации, оптимизм, жизнестойкость, толерантность к неопределенности, самоэффективность (Иванова и др., 2016) и динамика субъективного благополучия в условиях экономического кризиса. Уделяется внимание психологии безработного (Кабардов и др., 2010; Бендюков, 2007; Орлова, 2018).

\section{Организация и методики исследования}

\section{Дизайн и эмпирическая выборка исследования}

Э. Ротвел и Дж. Арнолд - авторы методики самовосприятия трудоспособности (Rothwell, Arnold, 2007). В данной статье приводятся результаты валидизации русскоязычной версии шкалы. Ротвел и Арнолд исходили из влияния индивидуальных особенностей на категоризацию социальной ситуации и оценку индивидуальных ресурсов ее преодоления, поэтому вопросы шкалы связаны с оценкой субъектом собственных возможностей. С учетом этих акцентов, а также с целью условного контроля внешних факторов (переменных локального рынка труда, экономической ситуации и иных внешних условий и организационных факторов) эмпирическую выборку нашего исследования составили работники крупного промышленного предприятия Поволжья.

Половозрастные и образовательные характеристики выборки исследования следующие: всего 715 чел., из них 477 мужчин, 238 женщин, возрастной диапазон $-18-75$ лет, средний возраст -36.2 , высшее образование имеют $37.8 \%$ респондентов, среднее профессиональное $-48.8 \%$, основное общее $13.9 \%$. Отметим, что половозрастные и образовательные параметры выборки близки к параметрам генеральной совокупности работающих граждан России (Федеральная служба государственной статистики, 2019).

Исследование носило срезовый характер, включало два этапа, на первом этапе анализировались надежность и факторная структура методики. Бланки методик были размещены в локальной сети организации, с целью снижения вероятности социально желательных ответов респондентам предоставлялась возможность заполнить их анонимно или указать имя (при желании).

На втором этапе исследования с интервалом в 1 месяц выполнялась проверка ретестовой надежности шкалы. В исследовании на данном этапе приняли участие 105 респондентов из числа указавших свое имя.

\section{Методики исследования}

Опросник самовосприятия трудоспособности Э. Ротвела и Дж. Арнолда изначально содержал 16 утверждений, в ходе валидизации авторы англоязычной версии сократили число утверждений до 11. Мы переводили и валидизировали на русском 11-пунктовую версию методики (выполнялся прямой и обратный перевод двумя независимыми билингвальными экспертами). Далее 
«рабочий» вариант методики был предложен для заполнения группе из 5 русскоязычных экспертов, с последующим обсуждением на предмет понятности формулирования утверждений, что позволило обеспечить семантическое тождество англоязычной и русскоязычной версий методик).

Описывая конструкцию методики, Ротвел и Арнолд приводят схему, которую образуют две оси: Самооценка (себя как специалиста и профессии), Рынок труда (внешний и внутриорганизационный).

Сочетание этих параметров образует четыре оцениваемые в методике субшкалы:

1) Оценка себя как специалиста в организации,

2) Самооценка собственной конкурентоспособности на рынке труда,

3) Воспринимаемая ценность должности в организации,

4) Оценка конкурентоспособности профессии на рынке труда.

Респонденты оценивают утверждения методики по 5-балльной шкале Ликерта.

Самооценка способности трудоустроиться вне организации (External selfperceived employability) оценивается на основании суммы параметров 2 и 4.

Самооценка способности трудоустроиться внутри организации (Internal selfperceived employability) (данная субшкала названа нами «Самооценка работником себя как специалиста и должности в организации») оценивается как сумма параметров 1 и 3. Оговоримся, что параметр 3 - Воспринимаемая ценность должности в организации - авторы оценивают на основании одного утверждения, что, на наш взгляд, не вполне соответствует логике конструирования психодиагностических методик, поэтому в нашем исследовании мы не диверсифицируем самооценку способности трудоустроиться внутри организации на шкалы, это, пожалуй, является наиболее существенным нареканием в адрес валидизируемой нами версии методики и, возможно, требует дополнительных исследований, направленных на включение в методику новых утверждений, с одной стороны, отражающих четыре выделенных Ротвелом и Арнолдом аспекта самовосприятия трудоспособности, с другой, опирающихся на особенности российской социально-экономической ситуации и культурного контекста.

Несмотря на отмеченное ограничение, методика оценки самовосприятия трудоспособности является экономичным и информативным инструментом.

Для валидизации шкалы мы использовали методики:

1. Удовлетворенности карьерой (Greenhaus et al., 1990) в адаптации А.Ю. Смирновой. Вслед за разработчиками оригинальной англоязычной версии мы предположили, что самовосприятие трудоспособности положительно связано с субъективной удовлетворенностью карьерой и что обе эти шкалы выступают своеобразными показателями субъективного карьерного успеха.

2. Диагностики воспринимаемой организационной поддержки (SPOS; Eisenberger et al., 1986) в адаптации А.Ю. Смирновой (2015б). Наше предположение: высокая оценка специалистом своей ценности для организации будет положительно связана с уровнем воспринимаемой поддержки, поскольку организационная поддержка отражает ценность сотрудника для организации и готовность инвестировать в него. 
3. Опросник поведения и переживания, связанного с работой (AVEM), в адаптации Т.И. Ронгинской (2002). Мы предположили, что самовосприятие трудоспособности положительно связано с чувством успешности в профессиональной деятельности, внутренним спокойствием и равновесием, активной стратегией решения проблем, уровнем профессиональных притязаний, чувством поддержки социального окружения, что диагностируемая по методике AVEM тенденция к отказу в ситуации неудачи отрицательно связана с самовосприятием трудоспособности.

4. Методика диагностики субъективной незащищенности в сфере труда X. Де Витта (JI Scale; Pienaar et al., 2013; Смирнова, 2015a). В данном случае наше предположение состояло в том, что работники, низко оценивающие свою трудоспособность, будут больше подвержены переживанию субъективной незащищенности в сфере труда.

Описательные статистики для методик исследования приведены в таблице 1.

\section{Описание эмпирических результатов исследования}

По большинству шкал статистика критерия Колмогорова-Смирнова показала значимый высокий результат на уровне $p=0,0001$, для выявления статистических связей между переменными применялся коэффициент ранговой корреляции $r$ Спирмена, приблизительно свободный от распределения метод конфирматорного факторного анализа, для оценки различий между половозрастными и профессиональными группами применялся критерий U МаннаУитни. Обработка данных проводилась с использованием программ SPSS Statistica 17, AMOS SPSS 22.

\section{Валидность шкальь}

Для проверки конвергентной и дискриминантой валидности субшкал шкалы Самооценки способности трудоустроиться рассчитывались корреляции с показателями других методик (таблица 1).

Общий уровень самовоспринимаемой трудоспособности не на высоком уровне, но значимо $(r=0.183, \mathrm{p}<0.001)$ связан с удовлетворенностью карьерой, при этом из всех субшкал методики самовосприятия трудоспособности наиболее выражена связь субшкалы Оценки себя как специалиста в организации с удовлетворенностью карьерой $(r=0.386, p<0.001)$, что соответствует, как мы считаем, содержанию обеих шкал - субъективный карьерный успех.

Воспринимаемая организационная поддержка также связана с субшкалой «Оценки себя как специалиста в организации» $(r=0.407, p<0.001)$ и не связана с субшкалами «Самооценка собственной конкурентоспособности на внешнем рынке труда» или «Воспринимаемая ценность профессии на внешнем рынке труда», что подтверждает конвергентную и дискриминантную валидность методики.

Как мы и предполагали, тенденция к отказу в ситуации неудачи отрицательно связана с самовосприятием трудоспособности. Ярким подтверждением валидности данных, получаемых посредством методики самовосприятия 
Таблица 1

Локальная валидность и связи субшкал

\begin{tabular}{|c|c|c|c|c|c|c|c|c|}
\hline & $\mathbf{1 7}$ & $\mathbf{1 8}$ & $\mathbf{1 9}$ & $\mathbf{2 0}$ & $\mathbf{2 1}$ & $\mathbf{M}$ & $\mathbf{S D}$ & $\mathbf{A}$ \\
\hline 1 & 0.033 & $0.194^{* *}$ & $0.225^{* *}$ & $0.300^{* *}$ & $0.215^{* *}$ & 21.88 & 2.95 & 0.479 \\
\hline 2 & $0.154^{* *}$ & $0.334^{* *}$ & $0.329^{* *}$ & $0.358^{* *}$ & $0.359^{* *}$ & 22.75 & 3.96 & 0.714 \\
\hline 3 & $0.288^{* *}$ & $0.353^{* *}$ & $0.377^{* *}$ & $0.367^{* *}$ & $0.442^{* *}$ & 20.90 & 3.89 & 0.744 \\
\hline 4 & $0.192^{* *}$ & $0.275^{* *}$ & $0.225^{* *}$ & $0.257^{* *}$ & $0.308^{* *}$ & 20.35 & 3.46 & 0.608 \\
\hline 5 & $0.113^{* *}$ & $0.273^{* *}$ & $0.235^{* *}$ & $0.385^{* *}$ & $0.314^{* *}$ & 23.81 & 2.98 & 0.751 \\
\hline 6 & $-0.081^{*}$ & $-0.086^{*}$ & $-0.089^{*}$ & $-0.132^{* *}$ & $-0.132^{* *}$ & 14.23 & 3.34 & 0.726 \\
\hline 7 & 0.037 & 0.024 & -0.026 & $-0.081^{*}$ & 0.002 & 19.18 & 4.38 & 0.807 \\
\hline 8 & 0.031 & $0.261^{* *}$ & $0.256^{* *}$ & $0.364^{* *}$ & $0.251^{* *}$ & 24.74 & 3.4 & 0.754 \\
\hline 9 & $0.155^{* *}$ & $0.221^{* *}$ & $0.275^{* *}$ & $0.279^{* *}$ & $0.294^{* *}$ & 20.36 & 3.64 & 0.673 \\
\hline 10 & $0.172^{* *}$ & $0.322^{* *}$ & $0.353^{* *}$ & $0.395^{* *}$ & $0.373^{* *}$ & 22.82 & 3.15 & 0.616 \\
\hline 11 & $-0.087^{*}$ & 0.061 & $0.142^{* *}$ & $0.257^{* *}$ & $0.079^{*}$ & 18.82 & 4.0 & 0.769 \\
\hline 12 & $-0.127^{* *}$ & $-0.269^{* *}$ & $-0.378^{* *}$ & $-0.499^{* *}$ & $-0.382^{* *}$ & 9.31 & 2.83 & 0.734 \\
\hline 13 & $-0.121^{* *}$ & $-0.155^{* *}$ & $-0.163^{* *}$ & $-0.189^{* *}$ & $-0.207^{* *}$ & 7.55 & 2.36 & 0.792 \\
\hline 14 & $-0.128^{* *}$ & $-0.320^{* *}$ & $-0.378^{* *}$ & $-0.462^{* *}$ & $-0.378^{* *}$ & 15.31 & 4.78 & 0.715 \\
\hline 15 & -0.041 & $0.091^{*}$ & $0.196^{* *}$ & $0.407^{* *}$ & $0.167^{* *}$ & 32.55 & 7.08 & 0.878 \\
\hline 16 & 0.001 & 0.075 & $0.164^{* *}$ & $0.386^{* *}$ & $0.183^{* *}$ & 17.33 & 3.52 & 0.86 \\
\hline 17 & 1.000 & $0.410^{* *}$ & $0.412^{* *}$ & $0.170^{* *}$ & $0.762^{* *}$ & 12.68 & 2.78 & 0.760 \\
\hline 18 & $0.410^{* *}$ & 1.000 & $0.367^{* *}$ & $0.400^{* *}$ & $0.753^{* *}$ & 11.77 & 1.95 & 0.595 \\
\hline 19 & $0.412^{* *}$ & $0.367^{* *}$ & 1.000 & $0.437^{* *}$ & $0.639^{* *}$ & 3.52 & 0.86 & - \\
\hline 20 & $0.170^{* *}$ & $0.400^{* *}$ & $0.437^{* *}$ & 1.000 & $0.627^{* *}$ & 11.43 & 1.90 & 0.529 \\
\hline 21 & $0.762^{* *}$ & $0.753^{* *}$ & $0.639^{* *}$ & $0.627^{* *}$ & 1.000 & 39.41 & 5.51 & - \\
\hline
\end{tabular}

Примечание. 1 - SU (Чувство социальной поддержки), 2 - LZ (Удовлетворенность жизнью), 3 - ЕЕ (Чувство успешности в профессиональной деятельности), 4 - IR (Внутреннее спокойствие и равновесие), 5 - ОР (Активная стратегия решения проблем), 6 - RT (Тенденция к отказу в ситуации неудачи), 7 - DF (Способность поддерживать дистанцию по отношению к работе), 8 - PS (Стремление к совершенству), 9 - VB (Готовность к энергетическим затратам), 10 - ВЕ (Профессиональные притязания), 11 - ВА (Субъективное значение деятельности), 12 Когнитивная субъективная незащищенность, 13 - Аффективная субъективная незащищенность, 14 - Субъективная незащищенность в целом, 15 - Воспринимаемая поддержка, 16 Удовлетворенность карьерой, 17 - Оценка востребованности профессии на рынке труда, 18 Оценка собственной конкурентоспособности на рынке труда, 19 - Оценка важности должности в организации, 20 - Самооценка себя как специалиста в организации, 21 - Самовосприятие трудоспособности общее.

$$
{ }^{*}-p<0.05,{ }^{* *}-p<0.001 \text {. }
$$


трудоспособности, выступает ее отрицательная связь с переживанием субъективной незащищенности в сфере труда (от $r=-0.499$ до $r=-0.121, p<0.001$ ).

Данные корреляции в некоторой степени служат подтверждением критериальной валидности, хотя для ее полной проверки, предполагающей соотношение диагноза и прогноза, получаемого посредством методики, в связи с объективно измеряемым показателем, требовался бы совершенно иной дизайн исследования, а именно лонгитюдное исследование респондентов, находящихся под угрозой увольнения, уволенных, сопоставления результатов самооценки способности найти работу и фактического быстрого трудоустройства, однако такой дизайн тоже не лишен недостатков (не включает внутриорганизационного аспекта трудоспособности, исключает респондентов, для которых угроза увольнения не реализовалась в фактическом увольнении); таким образом, корреляции же служат и для подтверждения критериальной валидности методики, хотя это и накладывает определенные ограничения, типичные для подобных методик, связанные с проблемой оценки своей эффективности и фактической эффективностью.

Подтверждением конструктной валидности методики выступает надежность-согласованность методики (рассчитанная на основании $\alpha$ Кронбаха), результаты приведены в таблице 2, а также конфирматорный факторный анализ (таблица 3). Метод - приблизительно свободный от распределения (asymptotically distribution-free); (Наследов, 2013).

Таблица 2

Надежность-согласованность методики

\begin{tabular}{|c|l|c|c|c|c|c|}
\hline № & \multicolumn{1}{|c|}{ Наименование параметра } & $\mathbf{M}$ & $\mathbf{S D}$ & $\boldsymbol{\alpha}$ & $\begin{array}{c}\boldsymbol{\alpha} \text { при уда- } \\
\text { лении } \\
\text { пункта }\end{array}$ & $\begin{array}{c}\text { А, основанное } \\
\text { на стандартных } \\
\text { пунктах }\end{array}$ \\
\hline 1 & $\begin{array}{l}\text { Оценка востребованности про- } \\
\text { фессии на рынке труда }\end{array}$ & 12.68 & 2.78 & 0.761 & $0.796^{* * *}$ & 0.763 \\
\hline 2 & $\begin{array}{l}\text { Самооценка собственной конку- } \\
\text { рентоспособности на внешнем } \\
\text { рынке труда }\end{array}$ & 11.77 & 1.95 & 0.595 & $0.393-0.591$ & 0.606 \\
\hline 3 & $\begin{array}{l}\text { Оценка важности должности в } \\
\text { организации }\end{array}$ & 3.52 & 0.86 & - & - & - \\
\hline 4 & $\begin{array}{l}\text { Самооценка себя как специали- } \\
\text { ста в организации }\end{array}$ & 11.47 & 1.90 & 0.529 & $0.37-0.47$ & 0.53 \\
\hline 5 & $\begin{array}{l}\text { Самовосприятие трудоспособ- } \\
\text { ности общее }\end{array}$ & 39.41 & 5.28 & 0.771 & $\begin{array}{c}0.746- \\
0.782^{* * * *}\end{array}$ & 0.772 \\
\hline 6 & $\begin{array}{l}\text { Воспринимаемая способность } \\
\text { трудоустроиться вне организации }\end{array}$ & 24.55 & 3.95 & 0.754 & $0.761^{*}$ & 0.753 \\
\hline 7 & $\begin{array}{l}\text { Воспринимаемая способность } \\
\text { трудоустроиться в организации }\end{array}$ & 15.0 & 2.42 & 0.638 & $0.642^{* *}$ & 0.640 \\
\hline
\end{tabular}

Примечание. * - при удалении п. $2 ;{ }^{*} *$ - при удалении п. 4; *** - при удалении пункта 10; **** - при удалении п. 2 . 
Таблица 3

Результаты проверки факторной структуры методики

\begin{tabular}{|c|c|c|c|c|}
\hline Параметр & $\begin{array}{c}\text { 3-факторная } \\
\text { модель полная }\end{array}$ & $\begin{array}{c}\text { 3-факторная модель, } \\
\text { удаленный п. 2 }\end{array}$ & $\begin{array}{c}\text { 2-факторная } \\
\text { модель }\end{array}$ & $\begin{array}{c}\text { 1-факторная } \\
\text { модель }\end{array}$ \\
\hline$\chi^{2}$ & 129.60 & 77.577 & 145.536 & 131.821 \\
\hline $\mathrm{df}$ & 40 & 29 & 26 & 31 \\
\hline $\mathrm{CMIN} / \mathrm{DF}$ & 3.240 & 2.675 & 5.598 & 4.252 \\
\hline $\mathrm{GFI}$ & 0.912 & 0.944 & 0.905 & 0.920 \\
\hline $\mathrm{AGFI}$ & 0.855 & 0.893 & 0.835 & 0.859 \\
\hline $\mathrm{CFI}$ & 0.688 & 0.819 & 0.590 & 0.680 \\
\hline RMSEA & 0.066 & 0.057 & 0.096 & 0.081 \\
\hline PCLOSE & 0.02 & 0.216 & 0.000 & 0.000 \\
\hline RMSEA (HI 90) & $0.053-0.020$ & $0.042-0.072$ & $0.081-0.112$ & $0.67-0.095$ \\
\hline
\end{tabular}

Надежность $\alpha$ не по всем субшкалам превышает уровень 0.7 , считающийся минимально приемлемым, однако отметим, что $\alpha$ имеет тенденцию недооценки надежности шкал с малым количеством пунктов, в отличие от его аналога омеги Макдональда, применение которого позволяет получить похожие результаты (Deng, Chan, 2017), но также нередко не улучшает показатели при работе со шкалами с ограниченным количеством пунктов (Сергеева и др., 2016).

Следует отметить, что при удалении п. 2 «Мое окружение в организации (где я работаю) помогает мне в карьере»; п. 4 «Навыки, которые я получил(а) на моей теперешней работе, пригодятся и в другой должности вне организации, где я работаю», и п. 10 «Любой с моим уровнем навыков и знаний, подобным опытом работы будет высоко цениться работодателями» $\alpha$ повышается, однако последующий анализ факторной структуры методики (и ухудшение показателей CMIN/DF, GFI, AGFI, CFI, RMSEA, PCLOSE) свидетельствовал в пользу сохранения п. 4 и 10, и удаления из методики только п. 2. Это единственный пункт, не столько ориентированный на оценку себя как профессионала или должности, сколько апеллирующий к практике взаимодействия сотрудников между собой, которая может быть конкурентной, в особенности в ситуации нестабильности в организации; данный пункт скорее действительно не отражает восприятия работником собственной трудоспособности.

Отметим, что приведенные в таблице 3 индексы 3-факторной модели являются достаточно низкими с позиции строгой математической теории, чтобы делать вывод о соответствии модели данным (Hu, Bentler, 1998). Однако в современной математической статистике, практике разработки и адаптации иноязычных тестов вопрос выбора порога критических значений является дискуссионным, равно как и выбор индексов оценки соответствия модели, которые одни специалисты предлагают строго регламентировать (American Educational Research Association, 2014), другие допускают вариативность математической логики (International Test Commission, 2017). В нашем случае для 
оценки соответствия апостериорной математической модели исходным данным могут быть применены более «мягкие» Значения индексов согласия, поскольку размер выборки достаточен (Наследов, 2013, с. 356). Отсутствие многомерной нормальности распределения переменных накладывает ограничения на применение метода максимального правдоподобия для выполнения КФА, однако в качестве альтернативы может быть использован приблизительно свободный от распределения метод (asymptotically distribution-free), что также делает возможным размер выборки нашего исследования ( $\mathrm{N}=715$, более 400-500 наблюдений) (Там же, с. 349). Решение о соответствии модели исходным данным, согласно А.Н. Наследову, принимается на основе не менее трех-пяти критериев КФА, выбирается модель с наилучшими числовыми значениями индексов. При этом наиболее робастным является RMSEA (Наследов, 2013). В нашем случае наилучшими показателями отличается 3-факторная модель. Она характеризуется приемлемым соответствием эмпирическим данным $\chi^{2}=77.577, \mathrm{df}=29, \mathrm{CMIN} / \mathrm{DF} 2.675, \mathrm{P}=0.000, \mathrm{GFI}=0.944$, $\mathrm{AGFI}=0.893, \mathrm{CFI}=0.819, \mathrm{RMSEA}=0.057$ [90\% CI 0.042-0.072], $\mathrm{PCLOSE}=0.216$. Так, на основании оценки факторной структуры методики методом КФА нами была эмпирически обоснована 3-факторная структура методики, включающая шкалы: Самооценка работником себя как специалиста и должности в организации $(\alpha=0.642)$, Самооценка работником себя на внешнем рынке труда $(\alpha=0.595)$, Воспринимаемая ценность профессии на внешнем рынке труда $(\alpha=0.761)$. Утверждение 2 было нами исключено из методики. Не все показатели $\alpha$ более 0.7 мы обсуждали выше, однако отметим, что адаптированные версии тестов, имеющие аналогичные показатели, нередко рассматриваются как достаточно надежные (Hogrefe LTD, 2020; и др.).

\section{Тест-ретестовая надежность шкаль}

Ретестовая надежность методики, рассчитанная по данным корреляции результатов повторного тестирования 105 респондентов с интервалом в один месяц, составила от 0.56 для субшкалы Воспринимаемая ценность должности в организации до 0.72 для субшкалы Самооценка собственной конкурентоспособности на внешнем рынке труда, что подтверждает тест-ретестовую надежность шкалы. Русскоязычная версия методики самовосприятия трудоспособности (Self-Perceived Employability Scale; Rothwell, Arnold, 2007) может применяться в исследовательских и практических целях, организационном и индивидуальном консультировании.

\section{Нормирование методики самовосприятия трудоспособности}

Так как распределение сырых оценок в нашей выборке не соответствует нормальному, мы провели нелинейную нормализацию. Следует отметить, что наиболее распространенным способом такой нормализации является перевод сырых баллов в систему стенайнов, предполагающую выделение 4, 7, 12, 17\% низких и высоких, а также 20\% центральных значений. Однако данная система 
не лишена субъективности в отнесении первичных эмпирических значений к конкретным стенайнам, поскольку количество респондентов с определенными баллами может превосходить эти процентные группы. Обнаружив такие затруднения, мы предпочли шкалу процентилей, а также анализ медианных значений. Вместе с тем среднее значение и стандартное отклонение, которые обычно не показательны в случае несоответствия нормальному распределению, в нашем случае достаточно приближены к значению медианы, а потому также могут быть учтены. Результаты шкалирования приведены в таблице 4.

Таблица 4

Статистические нормы методики самовосприятия трудоспособности

\begin{tabular}{|c|c|c|c|c|c|}
\hline $\mathbf{N}$ & Наименование показателя & 1 & 2 & 3 & 4 \\
\hline \multirow{8}{*}{$\mathrm{N}=715$ всего } & Среднее & 11.17 & 11.80 & 12.74 & 35.70 \\
\hline & Медиана & 11.00 & 12.00 & 13.00 & 35.00 \\
\hline & Мода & 11.00 & 12.00 & 12.00 & 36.00 \\
\hline & Стандартное отклонение & 1.89 & 1.94 & 2.73 & 5.14 \\
\hline & Дисперсия & 3.58 & 3.75 & 7.43 & 26.42 \\
\hline & Процентили: 25 & 10.00 & 11.00 & 11.00 & 32.00 \\
\hline & 50 & 11.00 & 12.00 & 13.00 & 35.00 \\
\hline & 75 & 12.00 & 13.00 & 14.00 & 39.00 \\
\hline \multirow{10}{*}{$\mathrm{N}=477$, муж. } & Среднее & 11.39 & 11.91 & 12.91 & 36.22 \\
\hline & Стандартная ошибка среднего & 0.088 & 0.094 & 0.13 & 0.24 \\
\hline & Медиана & 11.00 & 12.00 & 13.00 & 36.00 \\
\hline & Мода & 11.00 & 12.00 & 12.00 & 36.00 \\
\hline & Стандартное отклонение & 1.91 & 2.05 & 2.80 & 5.28 \\
\hline & Дисперсия & 3.664 & 4.190 & 7.82 & 27.86 \\
\hline & Процентили: 25 & 10.00 & 11.00 & 11.50 & 33.00 \\
\hline & 50 & 11.00 & 12.00 & 13.00 & 36.00 \\
\hline & 75 & 13.00 & 13.00 & 14.00 & 39.00 \\
\hline & $\begin{array}{l}\text { Асимптотическое значение различий } \\
\text { мужской и женской выборки }\end{array}$ & 0.00 & 0.01 & 0.03 & 0.00 \\
\hline \multirow{8}{*}{$\mathrm{N}=238$, жен. } & Среднее & 10.71 & 11.56 & 12.38 & 34.65 \\
\hline & Медиана & 10.00 & 12.00 & 12.00 & 34.00 \\
\hline & Мода & 10.00 & 12.00 & 12.00 & 31.00 \\
\hline & Стандартное отклонение & 1.76 & 1.67 & 2.54 & 4.69 \\
\hline & Дисперсия & 3.10 & 2.80 & 6.47 & 21.99 \\
\hline & Процентили: 25 & 9.00 & 10.00 & 11.00 & 31.00 \\
\hline & 50 & 10.00 & 12.00 & 12.00 & 34.00 \\
\hline & 75 & 12.00 & 13.00 & 14.00 & 37.00 \\
\hline
\end{tabular}

Примечание. 1 - Самооценка работником себя как специалиста и должности в организации, 2 - Самооценка собственной конкурентоспособности на рынке труда, 3 - Оценка конкурентоспособности профессии на рынке труда, 4 - Самовосприятие трудоспособности, общий уровень. 
Таблица 4 (продолжение)

\begin{tabular}{|c|c|c|c|c|c|}
\hline $\mathbf{N}$ & Наименование показателя & 1 & 2 & 3 & 4 \\
\hline \multirow{10}{*}{$\begin{array}{l}\mathrm{N}=557, \\
\text { до } 30 \text { лет }\end{array}$} & Среднее & 10.92 & 11.59 & 12.7199 & 35.23 \\
\hline & Медиана & 11.00 & 12.00 & 13.00 & 35.00 \\
\hline & Мода & 11.00 & 12.00 & 12.00 & 36.00 \\
\hline & Стандартное отклонение & 1.75 & 1.75 & 2.485 & 4.56 \\
\hline & Дисперсия & 3.06 & 3.07 & 6.17 & 20.76 \\
\hline & Процентили: 25 & 10.00 & 11.00 & 11.00 & 32.00 \\
\hline & 50 & 11.00 & 12.00 & 13.00 & 35.00 \\
\hline & 75 & 12.00 & 13.00 & 14.00 & 38.00 \\
\hline & $\begin{array}{l}\text { Асимптотическое значение различий } \\
\text { между выборками до } 30 \text { и от } 30 \text { до } 50\end{array}$ & 0 & 0 & 0.345 & 0 \\
\hline & $\begin{array}{l}\text { Асимптотическое значение различий } \\
\text { между группами до } 30 \text { и после } 50\end{array}$ & 0.001 & 0.002 & 0.978 & 0.021 \\
\hline \multirow{9}{*}{$\begin{array}{l}\mathrm{N}=108 \\
30-50 \text { лет }\end{array}$} & Среднее & 12.13 & 12.54 & 12.84 & 37.51 \\
\hline & Медиана & 12.00 & 13.00 & 13.00 & 37.00 \\
\hline & Мода & 11.00 & $12.00 \mathrm{a}$ & 14.00 & 36.00 \\
\hline & Стандартное отклонение & 2.20 & 2.47 & 3.45 & 6.75 \\
\hline & Дисперсия & 4.86 & 6.12 & 11.910 & 45.523 \\
\hline & Процентили: 25 & 11.00 & 11.00 & 11.00 & 33.00 \\
\hline & 50 & 12.00 & 13.00 & 13.00 & 37.00 \\
\hline & 75 & 14.00 & 14.00 & 15.00 & 40.75 \\
\hline & $\begin{array}{l}\text { Асимптотическое значение разли- } \\
\text { чий } 30-50 \text { и старше } 50\end{array}$ & 0.517 & 0.764 & 0.756 & 0.99 \\
\hline \multirow{8}{*}{$\begin{array}{c}\mathrm{N}=50, \\
50 \text { и старше }\end{array}$} & Среднее & 11.82 & 12.50 & 12.68 & 37.00 \\
\hline & Медиана & 12.00 & 13.00 & 13.00 & 37.00 \\
\hline & Мода & 11.00 & 15.00 & 16.00 & 37.00 \\
\hline & Стандартное отклонение & 1.91 & 2.04 & 3.49 & 6.21 \\
\hline & Дисперсия & 3.66 & 4.17 & 12.22 & 38.61 \\
\hline & Процентили: 25 & 10.00 & 11.00 & 10.00 & 31.75 \\
\hline & 50 & 12.00 & 13.00 & 13.00 & 37.00 \\
\hline & 75 & 13.00 & 14.00 & 15.25 & 42.00 \\
\hline
\end{tabular}

\section{Обсуждение результатов}

Резюмируя анализ эмпирических результатов, можно сделать заключение о приемлемой надежности Шкалы самовосприятия трудоспособности, а также валидности получаемых при помощи этой шкалы данных. Выполненный конфирматорный факторный анализ подтверждает факторную структуру методики, хотя не все критерии переходят критические значения, однако именно предположенная нами трехфакторная структура методики подтверждается критериями согласия в сравнении с одно- и двухфакторной структурами. Надежность-согласованность субшкал «Самооценка собственной 
конкурентоспособности на внешнем рынке труда», «Воспринимаемая ценность профессии на внешнем рынке труда» преодолевает критическое значение $\alpha=0.7$, таким образом, русскоязычная версия Шкалы самовосприятия трудоспособности (Self-Perceived Employability Scale; Rothwell, Arnold, 2007) позволяет получить достаточно валидные данные о внешнеорганизационном ракурсе самовосприятия трудоспособности. Не достигли соответствующего показателя $\alpha$ субшкалы, предназначенные для оценки способности трудоустроиться внутри организации. К сожалению, дизайн нашего исследования, для которого мы намеренно выбрали одну организацию, чтобы условно контролировать внешние переменные, не позволяет предположить, является ли это следствием особенностей конкретной организации или того, что мы объединили в одну субшкалу утверждения, предназначенные для диагностики двух субшкал оригинальной версии методики, направленных на оценку работником собственной способности трудоустроиться внутри организации: субшкалу «Самооценка себя как специалиста в организации» и субшкалу «Воспринимаемая ценность должности в организаци».

Остается открытым вопрос о влиянии организационного контекста на оценку работниками собственной трудоспособности внутри организации, но для этой цели необходимо сопоставление данных разных организаций, что также не предусмотрено условиями нашего исследования. Конвергентная, дискриминантная, критериальная валидность и ретестовая надежность шкалы удовлетворительны, что подтверждается данными корреляционного анализа.

Как мы и предположили, методика AVEM позволила получить широкий спектр данных. Показательна выраженная связь всех субшкал Шкалы самовоспринятия трудоспособности с чувством успешности в профессиональной деятельности, внутренним спокойствием и равновесием, активной стратегией решения проблем, уровнем профессиональных притязаний, чувством поддержки социального окружения. Стремление к совершенству и субъективное значение деятельности демонстрируют значимую корреляцию со способностью трудоустроиться внутри организации, но не вне ее. Это также рационально объясняется с позиции теорий межличностного взаимодействия как обмена: дорожащие своей работой и выполняющие задания на наиболее высоком уровне качества работники обретают в организации бо́льшие перспективы. Обнаруженные связи подтверждают, что особенности поведения и переживаний, связанных с работой, могут выступать ресурсами личности в ситуации угрозы потери работы и необходимости сохранения занятости или поиска новой работы (шкалы AVEM: Активная стратегия решения проблем, Стремление к совершенству, Готовность к энергетическим затратам, Внутреннее спокойствие и равновесие, Чувство поддержки социального окружения).

Полученные нами данные о связи воспринимаемой организационной поддержки $(r=0.407, p<0.001)$ с самооценкой специалистом себя в рамках организации подтверждают предположение об инвестировании организации в наиболее ценных для нее сотрудников. То, что организационная поддержка 
менее связана с ценностью профессиональной позиции в организации $(r=0.196$, $p<0.001)$, в сравнении с оценкой специалистом себя в рамках организации, на наш взгляд, еще раз подчеркивает тенденции быстрого устаревания знаний. Профессиональные компетенции требуют постоянного обновления, и именно индивидуальные особенности работника ценятся современным работодателем, профессиональные же компетенции наращиваются в ходе непрерывного обучения.

Выявленная более высокая самооценка респондентами-мужчинами своей самовоспринимаемой трудоспособности, как в целом по методике, так и по отдельным субшкалам, выступает дополнительным свидетельством более высокой ценности на рынке труда и карьерного успеха мужчин-работников.

Сотрудники в возрасте до 30 лет оценивают свою способность трудоустроиться ниже, чем сотрудники в возрасте от 30 до 50 лет, за исключением параметра «Оценка конкурентоспособности профессии на рынке труда». Действительно, молодые люди осваивают новые востребованные на рынке труда профессии, однако ценность молодых работников нередко ниже, чем работников среднего возраста, из-за отсутствия должного опыта работы.

Сотрудники в возрасте от 30 до 50 лет и сотрудники старше 50 лет в нашей выборке не различаются по самовосприятию трудоспособности. Однако в других исследованиях можно найти данные, что сотрудники более старшего возраста ниже оценивают свою трудоспособность (Rothwell et al., 2006; Vantilborgh et al., 2013).

Следует отметить, что обе эти группы в нашей выборке не столь многочисленные, как группа работников до 30 лет, в связи с чем требуется дополнительное накопление эмпирических данных, которое может внести уточнение в сравнение этих групп. Именно немногочисленность «средней» и «старшей» возрастных групп составляет ограничение нашего исследования. В связи с этим намечаются возможные направления дальнейших исследований - анализ самовосприятия трудоспособности работников старшей возрастной категории в аспекте связи возраста и образовательного уровня, иерархического статуса работника в организации, гендерных особенностей самовосприятия трудоспособности в российской выборке, а также влияния на самовосприятие трудоспособности семейного статуса работников и наличия детей.

\section{Литература}

Бендюков, М. А. (2007). Стадиальная модель ненормативного профессионально-обусловленного кризиса занятости. Известия Российского государственного педагогического университета им. А. И. Герцена, 9(47), 149-154.

Емельянова, Т. П. (2016). Коллективная память о советском прошлом: назад в СССР? Психологические исследования, 9(47). http://psystudy.ru

Иванова, Т. Ю., Леонтьев, Д. А., Рассказова, Е. И. (2016). Функции личностных ресурсов в ситуации экономического кризиса. Психология. Журнал Высшей школь экономики, 13(2), $323-346$. 
Кабардов, М. К., Аминов, Н. А., Гусев, С. А. (2010). Исследование специфики переживания события потери работы. Психологические исследования, 6(14). http://psystudy.ru

Минтруд России. (2017, 21 декабря). Госдума России одобрила в третьем чтении законопроект о сопровождаемой занятости инвалидов. https://mintrud.gov.ru/social/invalid-defence/403

Наследов, А. Н. (2013). IBM SPSS Statistics 20 и AMOS: профессиональный статистический анализ данных. СПб.: Питер.

Орлова, М. М. (2018). Объективные и субъективные факторы ситуации бедности у мужчин и женщин. В кн. Л. Н. Алсеновская (ред.), Организащионная психология: Люди и риски (с. 135-140). Саратов: ИЦ «Наука».

Ронгинская, Т. И. (2002). Синдром «выгорания» в социальных профессиях. Психологический журнал, 23(3), 85-95.

Сергеева, А. С., Кириллов, Б. А., Джумагулова, А. Ф. (2016). Перевод и адаптация краткого пятифакторного опросника личности (TIPI-RU): оценка конвергентной валидности, внутренней согласованности и тест-ретестовой надежности. Экспериментальная психология, 9(3), 138-154. https://doi.org/10.17759/exppsy.2016090311

Смирнова, А. Ю. (2015а). Двухкомпонентная модель субъективной незащищенности в сфере труда в зарубежных исследованиях: психологическое содержание и диагностика феномена Известия Саратовского университета. Новая серия. Серия Философия. Психология. Педагогика, 4, 99-106.

Смирнова, А. Ю. (2015б). Роль организационной поддержки в профессиональном развитии персонала. Акмеология, 4(56), 142-150.

Смирнова, А. Ю. (2018). Значение поддержки социального окружения в сохранении психологической защищенности работником в ситуации угрозы потери работы. Психологические исследования, 11(58), 10. http://psystudy.ru

Федеральная служба государственной статистики. (2019). Труд и занятость в России 2019. Статистический сборник. М.: Росстат. https://rosstat.gov.ru/storage/mediabank/ Trud_2019.pdf

Федеральная служба государственной статистики. (2020). Занятость и безработица в Российской Федерации в октябре 2020 года. https://rosstat.gov.ru/folder/70843/document/109518

Ссылки на зарубежные источники см. в разделе References.

\section{References}

American Educational Research Association, American Psychological Association, \& National Council on Measurement in Education (Eds.). (2014). Standards for educational and psychological testing. American Educational Research Association.

Bendyukov, M. A. (2007). Phasic model of non-normative profession-determined employment crisis. Izvestiya Rossiiskogo gosudarstvennogo pedagogicheskogo universiteta im. A. I. Gertsena [Izvestia: Herzen University Journal of Humanities E Sciences], 9(47), 149-154. (in Russian)

Bernstrøm, V. H., Drange, I., \& Mamelund, S. E. (2019). Employability as an alternative to job security. Personnel Review, 48(1), 234-248.

Berntson, E. (2008). Employability perceptions. Nature, determinants, and implications for health and well-being. Stockholm: Stockholm University. 
Berntson, E., Sverke, M., \& Marklund, S. (2006). Predicting perceived employability: Human capital or labour market opportunities? Economic and Industrial Democracy, 27(2), 223-244.

Deng, L., \& Chan, W. (2017). Testing the difference between reliability coefficients Alpha and Omega. Educational and Psychological Measurement, 77(2), 185-203. https://doi.org/10.1177/0013164416658325

Eisenberger, R., Huntington, R., Hutchinson, S., \& Sowa, D. (1986). Perceived organizational support. Journal of Applied Psychology, 71, 500-507.

Emelyanova, T. P. (2016). Collective memory about the Soviet past: back in USSR? Psikhologicheskie Issledovaniya, 9(47). Retrieved from http://psystudy.ru (in Russian)

Federal'naya sluzhba gosudarstvennoi statistiki. (2019). Trud i zanyatost'v Rossii 2019. Statisticheskii sbornik [Labor and employment in Russia]. Moscow: Rosstat. https://rosstat.gov.ru/storage/mediabank/Trud_2019.pdf

Federal'naya sluzhba gosudarstvennoi statistiki. (2020). Zanyatost'i bezrabotitsa v Rossiiskoi Federatsii $v$ oktyabre 2020 goda [Employment and unemployment in the Russian Federation in January 2020]. https://rosstat.gov.ru/folder/70843/document/109518

Forrier, A., \& Sels, L. (2003). The concept employability: a complex mosaic. International Journal of Human Resources Development and Management, 3, 102-124.

Fugate, M., Kinicki, A. J., \& Ashforth, B. E. (2004). Employability: a psycho-social construct, its dimensions, and applications. Journal of Vocational Behavior, 65(1), 14-38.

Gardner, D. G., Huang, G., Pierce, J. L., Niu, X., \& Lee, C. L. (2010). Organization-based selfesteem: Relationships with psychological contracts and perceived employment opportunities. Academy of Management Best Papers Proceedings, 1, 1-6.

Greenhaus, J. H., Parasuraman, S., \& Wormley, W. M. (1990). Effects of race on organizational experiences, job performance evaluations, and career outcomes. Academy of Management Journal, 33(1), $64-86$.

Hillage, J., \& Pollard, E. (1998). Employability: developing a framework for policy analysis (Research report RR85). Institute for Employment Studies, DfEE, Brighton. https://www.researchgate.net/publication/225083565_Employability_Developing_a_framework_for_policy_analysis

Hogrefe LTD. (2020). Business-Focused Inventory of Personality (BIP). https://eu.hogrefe.com/shop/media/downloads/sample-reports/5507002_mr.pdf

Hu, L. T., \& Bentler, P. M. (1998). Fit indices in covariance structure modeling: Sensitivity to underparameterized model misspecification. Psychological Methods, 3(4), 424-453. https://doi.org/10.1037/1082-989X.3.4.424

International Test Commission. (2017). The ITC guidelines for translating and adapting tests (2nd ed.). https://www.intestcom.org/files/guideline_test_adaptation_2ed.pdf

Ivanova, T. Yu., Leontiev, D. A., \& Rasskazova, E. I. (2016). Functions of personality resources in a situation of economic crisis. Psychology. Journal of the Higher School of Economics, 3(2), 323-346. (in Russian)

Kabardov, M. K., Aminov, N. A., \& Gusev, S. A. (2010). The study of losing a job experience. Psikhologicheskie Issledovaniya, 6(14). http://psystudy.ru (in Russian)

Kanfer, R., Wanberg, C. R., \& Kantrowitz, T. M. (2001). Job search and employment: A personalitymotivational analysis and meta-analytic review. Journal of Applied Psychology, 86(5), 837-855.

Kanter, R. M. (1993). Employability Security. Business and Society Reviere, 87, 11-14.

Klandermans, B., \& van Vuuren, T. (1999). Job insecurity: Introduction. European Journal of Work and Organizational Psychology, 8(2), 145-153. 
Kluytmans, F., \& Ott, M. (1999). The management of employability in The Netherlands. European Journal of Work and Organizational Psychology, 8(2), 261-272.

Krause, J. S., \& Broderick, L. (2006). Relationship of personality and locus of control with employment outcomes among participants with spinal cord injury. Rehabilitation Counseling Bulletin, 49(2), 111-114.

Lowden, K., Hall S., Elliot D., \& Lewin J. (2011). Employers' perceptions of the employability skills of new graduates. London: Millbank/Edge SCRE Centre at the University of Glasgow.

Mallough, S., \& Kleiner, B. H. (2001). How to determine employability and wage earning capacity. Management Research News, 24(3/4), 118-122.

Mazalin, K., \& Parmac Kovacic, M. (2015). Determinants of higher education students' self-perceived employability. Drustvena Istrazivanja, 24(4), 509-529.

McKinsey Global Institute. (2017). Getting ready for the future of work. https://www.mckinsey.com/ business-functions/organization/our-insights/getting-ready-for-the-future-of-work

Mintrud Rossii. (2017, December 21). Gosduma Rossii odobrila v tret'em chtenii zakonoproekt o soprovozhdaemoi zanyatosti invalidov [The State Duma of Russia approved in the third reading the bill on the accompanied employment of people with disabilities]. https://mintrud.gov.ru/ social/invalid-defence/403

Moynihan, L. M., Roehling, M. V., LePine, M. A., \& Boswell, W. R. (2003). A longitudinal study of the relationships among job search self-efficacy, job interviews, and employment outcomes. Journal of Business \& Psychology, 18(2), 207-233.

Nasledov, A. N. (2013). IBM SPSS Statistics 20 i AMOS: professional'nyi statisticheskii analiz dannykh [IBM SPSS Statistics 20 and AMOS: professional statistical analysis]. Saint Petersburg: Piter.

Orlova, M. M. (2018). Ob"ektivnye i sub"ektivnye faktory situatsii bednosti u muzhchin i zhenshchin [Objective and subjective factors of the situation of poverty for both men and women]. In L. N. Alsenovskaya (Ed.), Organizatsionnaya psikhologiya: Lyudi i riski [Organizational psychology: people and risks] (pp. 135-140). Saratov: Nauka.

Paviotti, G. (2020). Self-perceived employability and implications for learning design: An exploratory case study. Education Sciences and Society, 2, 170-193.

Pienaar, J., De Witte, H., Hellgren, J., \& Sverke, M. (2013). The cognitive/affective distinction of job insecurity: Validation and differential relations. Southern African Business Review, 7(2). https://www.ajol.info/index.php/sabr/article/view/110912/100675

Pinquart, M., Juang, L. P., \& Silbereisen, R. K. (2003). Self-efficacy and successful school-to-work transition: a longitudinal study. Journal of Vocational Behavior, 63(3), 329-346.

Pitan, O. S., \& Muller, C. (2020). Students' self-perceived employability (SPE): Main effects and interactions of gender and field of study. Higher Education, Skills and Work-based Learning, 10(2), 355-368.

Ronginskaya, T. I. (2002). Syndrome of burning-out in social professions. Psychological Journal, 23(3), 85-95. (in Russian)

Rothwell, A., \& Arnold, J. (2007). Self-perceived employability: development and validation of a scale. Personnel Review, 36(1), 23-41. https://doi.org/10.1108/00483480710716704

Rothwell, A., Herbert, I., \& Rothwell, F. (2008). Self-perceived employability: Construction and initial validation of a scale for university students. Journal of Vocational Behavior, 73, 1-12. https://doi.org/10.1016/j.jvb.2007.12.001

Rothwell, A., Jewell, S., \& Hardie, M. (2009). Self-perceived employability: Investigating the responses of post-graduate students. Journal of Vocational Behavior, 75, 152-161. 
Sergeeva, A. S., Kirillov, B. A., \& Dzhumagulova, A. F. (2016). Translation and adaptation of short five factor personality questionnaire (TIPI-RU): convergent validity, internal consistency and testretest reliability evaluation. Eksperimental'naya Psikhologiya [Experimental Psychology], 9(3), 138-154. https://doi.org/10.17759/exppsy.2016090311 (in Russian)

Smirnova, A. Yu. (2015a). The two-dimensional approach to job insecurity in foreign literature: Psychological content and measurement. Izvestiya Saratozskogo universiteta. Novaya seriya. Seriya Filosofiya. Psikhologiya. Pedagogika, 4, 99-106. (in Russian)

Smirnova, A. Yu. (2015b). The perceived organizational support as a factor of professional development of the personnel. Akmeologya, 4(56), 142-150. (in Russian)

Smirnova, A. Yu. (2018). The impact of social support on psychological security of the employee in job loss threatened situation. Psikhologicheskie Issledovaniya, 11(58), 10. http://psystudy.ru (in Russian)

Vantilborgh, T., Bidee, J., Pepermans, R., Willems, J., Huybrechts, G., \& Jegers, M. (2013). From "getting" to "giving": Exploring age-related differences in perceptions of and reactions to psychological contract balance. European Journal of Work and Organizational Psychology, 22(3), 293-305.

Vargas, R., Sánchez-Queija, M. I., Rothwell, A., \& Parra, Á. (2018). Self-perceived employability in Spain. Education + Training, 60(3), 226-237. https://doi.org/10.1108/ET-03-2017-0037 
Приложение 1

\section{Бланк методики}

Оцените степень вашего согласия с каждым из утверждений по шкале от $1-$ «Совершенно не согласен» до $5-$ «Совершенно согласен» $(p=0.0001)$.

\begin{tabular}{|c|c|c|}
\hline Утверждения методики & Принадлежность к фактору & SRW* \\
\hline $\begin{array}{l}\text { 1. Даже если в организации (где я работаю) будет } \\
\text { сокращение, я уверен, что останусь }\end{array}$ & \multirow{3}{*}{$\begin{array}{l}\text { Самооценка работником } \\
\text { себя как специалиста и } \\
\text { должности в организации }\end{array}$} & 0.369 \\
\hline $\begin{array}{l}\text { 2. Мое окружение в организации (где я работаю) } \\
\text { помогает мне в карьере }\end{array}$ & & - \\
\hline $\begin{array}{l}\text { 3. Я считаю, что мои возможности в организации, } \\
\text { где я работаю, возрастут, даже если то, что я буду } \\
\text { делать, будет отличаться от того, чем я зани- } \\
\text { маюсь сейчас }\end{array}$ & & 0.428 \\
\hline $\begin{array}{l}\text { 4. Навыки, которые я получил(а) на моей тепе- } \\
\text { решней работе, пригодятся и в другой должности } \\
\text { вне организации, где я работаю }\end{array}$ & \multirow{3}{*}{$\begin{array}{l}\text { Самооценка работником } \\
\text { себя на внешнем рынке } \\
\text { труда }\end{array}$} & 0.461 \\
\hline $\begin{array}{l}\text { 5. Я могу легко переобучиться, чтобы стать более } \\
\text { трудоспособным }\end{array}$ & & 0.532 \\
\hline $\begin{array}{l}\text { 6. Я хорошо знаю, что вне организации, где я } \\
\text { работаю, для меня есть масса возможностей, даже } \\
\text { если они отличаются от того, чем я занимаюсь } \\
\text { сейчас }\end{array}$ & & 0.667 \\
\hline $\begin{array}{l}\text { 7. Среди работников, которые делают ту же } \\
\text { самую работу, что и я, я высоко ценюсь в своей } \\
\text { организации }\end{array}$ & $\begin{array}{l}\text { Самооценка работником } \\
\text { себя как специалиста и } \\
\text { должности в организации } \\
\end{array}$ & 0.608 \\
\hline $\begin{array}{l}\text { 8. Если мне понадобится, я легко найду такую же } \\
\text { работу, как та, на которой сейчас работаю, в такой } \\
\text { же организации }\end{array}$ & \multirow{4}{*}{$\begin{array}{l}\text { Воспринимаемая ценность } \\
\text { профессии на внешнем } \\
\text { рынке труда }\end{array}$} & 0.860 \\
\hline $\begin{array}{l}\text { 9. Я легко найду такую же работу в любой орга- } \\
\text { низации }\end{array}$ & & 0.822 \\
\hline $\begin{array}{l}\text { 10. Любой с моим уровнем навыков и знаний, } \\
\text { подобным опытом работы будет высоко цениться } \\
\text { работодателями }\end{array}$ & & 0.530 \\
\hline $\begin{array}{l}\text { 11. Я найду любую работу, где угодно, пока мои } \\
\text { навыки и опыт соответствуют требованиям }\end{array}$ & & 0.569 \\
\hline
\end{tabular}

